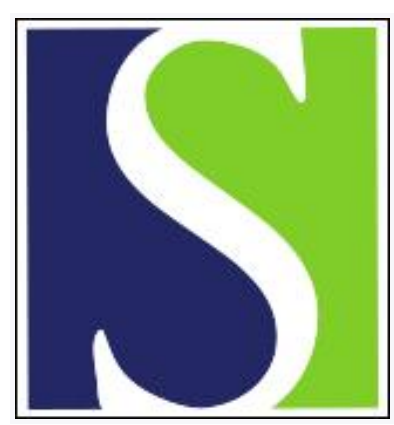

Scand J Work Environ Health 1987;13(3):252-254

https://doi.org/10.5271/sjweh.2055

Issue date: Jun 1987

Asbestos-associated lung effects in car mechanics.

by Marcus K, Jarvholm BG, Larsson S

This article in PubMed: www.ncbi.nlm.nih.gov/pubmed/3616555

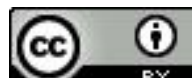

This work is licensed under a Creative Commons Attribution 4.0 International License 


\title{
Asbestos-associated lung effects in car mechanics
}

\author{
by Kjell Marcus, MD, ${ }^{1}$ Bengt G Järvholm, $M D,{ }^{2}$ Sven Larsson, $M^{3}$
}

\begin{abstract}
MARCUS K, JÄRVHOLM BG, LARSSON S. Asbestos-associated lung effects in car mechanics. Scand $J$ Work Environ Health 13 (1987) 252-254. In a study of the possible impact of asbestos exposure on car mechanics, 925 car mechanics and 109 referents (office workers in car-repair firms) were examined. They took part in a health screening in 1977-1981. The forced expiratory volumes in $1 \mathrm{~s}$ and the forced vital capacities of the car mechanics were close to the predicted values and did not differ from the findings of the referents. Pleural plaques were found in 41 of the mechanics but in none of the referents. Only minor changes were detected in the chest radiographs ie, $1 / 1$ or less according to the ILO-U/C classification. It is concluded that asbestos exposure can generally cause pleural plaques in car mechanics but no substantial impairment of lung function.
\end{abstract}

Key terms: asbestosis, lung function, occupation, pleural plaques.

The health effects of heavy exposure to asbestos are well known. A rather large number of workers is exposed to asbestos during the repair of cars. Asbestos is used in friction materials such as brake linings. The clean blowing of brake drums and the smoothing of the brake linings cause peak exposures to asbestos. As these periods of exposure are very short, the cumulative dose of asbestos exposure is rather low for mechanics when compared, for example, with that of insulation workers. Little is known about the health effects of such relatively low exposure.

In the late 1970s a health screening was offered to mechanics in Göteborg. This study describes the findings of that survey. The objective of the analysis was to determine whether asbestos exposure during car repair impairs respiratory function or causes pleural plaques or asbestosis in the mechanics performing the job.

\section{Subjects and methods}

Between 1977 and 1980 a free health examination was offered in Sweden to persons who had been exposed to asbestos at work. In Göteborg most car repair firms are associated with the same occupational health center that organized the health screening.

Participation in the screening was voluntary, but all persons who were or who had been exposed to asbestos were actively encouraged to participate. The response rate is not exactly known, but from the number of

1 Motorhälsan, Göteborg, Sweden.

2 Department of Occupational Medicine, Sahlgren Hospital, Göteborg, Sweden.

3 Department of Occupational Lung Medicine, Renströmska sjukhuset, Göteborg, Sweden.

Reprint requests to: Dr BG Järvholm, Department of Occupational Medicine, St Sigfridsgatan 85, S-412 66 Göteborg, Sweden. mechanics associated with the health center, we estimate that the survey covered more than $90 \%$ of the mechanics employed at the time. We restricted the analysis to men, as very few women had such jobs.

During the analysis we found that some office workers had also been examined. Their exposure to asbestos was negligible, and we therefore analyzed their data separately to provide information on a reference group. A total of 925 mechanics and 109 office workers were examined (table 1). Thirty-four percent of the mechanics and $32 \%$ of the office workers were life-long nonsmokers.

Every man answered a questionnaire about his occupational background, first exposure to asbestos, and total worktime in asbestos exposure. In almost all cases the worktime in asbestos exposure was found to be equivalent to the time from the start of asbestos exposure to the time of the examination, ie, the latency time. We therefore only analyzed the data stratifying for time since onset of exposure. The questionnaires were checked by nurses in the presence of the patients. After the questionnaires had been answered, all the men underwent spirometry on a calibrated dry bellow spirometer (Vitalograph). At least three technically acceptable recordings were made, and the best forced vital capacity (FVC) and forced expiratory volume in $1 \mathrm{~s}\left(\mathrm{FEV}_{1.0}\right)$ were selected from the curves. Trained nurses assisted with the spirometry.

A full-size chest radiograph (posterior-anterior and lateral views) was taken and read by one of three trained physicians. Pleural plaques were defined according to Thiringer et al (8). Their definition requires that the change be at least $5-\mathrm{mm}$ thick on the chest wall or $3-\mathrm{mm}$ thick on the diaphragm to be called a pleural plaque. Persons whose radiographs showed a suspiciously increased number of opacities and/or irregularities in the lung parenchyma and persons with a pathological spirometry of unknown origin were referred for further examination, ie, other lung physiological tests, a lung biopsy, etc. 
Table 1. Age distributions of the groups studied.

\begin{tabular}{lcc}
\hline Age group & Mechanics & Office workers \\
\hline$\leq 19$ & 50 & 1 \\
$20-29$ & 371 & 32 \\
$30-39$ & 245 & 29 \\
$40-49$ & 147 & 27 \\
$50-59$ & 92 & 14 \\
$60-69$ & 19 & 6 \\
$\geq 70$ & 1 & - \\
\hline Total & 925 & 109 \\
\hline
\end{tabular}

Table 3. Prevalence of pleural plaques in the different age groups.

\begin{tabular}{lcc}
\hline $\begin{array}{l}\text { Age group } \\
\text { (years) }\end{array}$ & $\begin{array}{c}\text { Number } \\
\text { of } \\
\text { workers }\end{array}$ & $\begin{array}{c}\text { Prevalence } \\
\text { of plaques } \\
(\%)\end{array}$ \\
\hline $30-39$ & 246 & $0.4^{\mathrm{b}}$ \\
$\quad$ Mechanics & 29 & 0.0 \\
Office workers & 148 & 6.0 \\
$40-49$ & 27 & 0.0 \\
Mechanics & & \\
Office workers & 93 & 25.0 \\
$50-59$ & 14 & 0.0 \\
Mechanics & 19 & 42.0 \\
Office workers & 6 & 0.0 \\
$60-69$ & & \\
Mechanics & & \\
Office workers & &
\end{tabular}

a No plaques were found in younger age groups.

b One individual, 39 years of age.

For a diagnosis of asbestosis we required at least two of the following criteria: (i) pathological chest radiograph, ie, 1/0 or more, (ii) findings in the lung physiology in agreement with fibrosis, or (iii) inspiratory rales on auscultation.

The differences between the mean values were tested with a two-tailed t-test, and only P-values of less than 0.05 were noted.

\section{Results}

The results of the spirometry indicated no changes in the lung function of the mechanics when compared to that of the office workers; the mechanics had, in fact, slightly better values. Neither were any changes indicated in comparison to the reference material (2), ie, the $\mathrm{FEV}_{1.0}$ and FVC were close to $100 \%$ of the predicted values (table 2). A multivariate analysis on smoking, age, and latency time did not indicate that an impaired respiratory function was associated with latency time (not shown in the tables).

Forty-one of the mechanics but none of the office workers were found to have pleural plaques (table 3). The frequency of plaques was highly dependent on the time since the onset of asbestos exposure. In mechanics with at least 40 years since the onset of exposure, $57 \%$ had pleural plaques $(\mathrm{N}=35)$, while the corresponding figures were $14 \%$ for mechanics with $30-39$ years
Table 2. Means and standard deviations of the forced expiratory volume in $1 \mathrm{~s}$ (FEV 1 ) and forced vital capacity (FVC) of the mechanics and office workers. The values are expressed as the percentage of the predicted value.

\begin{tabular}{|c|c|c|c|c|c|}
\hline \multirow{2}{*}{$\begin{array}{l}\text { Smoking } \\
\text { classification }\end{array}$} & \multirow{2}{*}{$\begin{array}{c}\text { Number } \\
\text { of } \\
\text { workers }\end{array}$} & \multicolumn{2}{|c|}{$\begin{array}{l}\mathrm{FEV}_{1.0} \\
(\%)\end{array}$} & \multicolumn{2}{|c|}{$\begin{array}{l}\text { FVC } \\
(\%)\end{array}$} \\
\hline & & Mean & SD & Mean & SD \\
\hline \multicolumn{6}{|l|}{ Nonsmokers } \\
\hline $\begin{array}{l}\text { Mechanics } \\
\text { Office workers }\end{array}$ & $\begin{array}{r}318 \\
35\end{array}$ & $\begin{array}{l}105 \\
106\end{array}$ & $\begin{array}{l}13.1 \\
16.0\end{array}$ & $\begin{array}{l}100 \\
98.8\end{array}$ & $\begin{array}{l}10.9 \\
12.0\end{array}$ \\
\hline \multicolumn{6}{|l|}{ Ex-smokers } \\
\hline $\begin{array}{l}\text { Mechanics } \\
\text { Office workers }\end{array}$ & $\begin{array}{r}188 \\
19\end{array}$ & $\begin{array}{c}107^{* *} \\
99.8\end{array}$ & $\begin{array}{l}13.9 \\
19.1\end{array}$ & $\begin{array}{c}100^{* *} \\
93.7\end{array}$ & $\begin{array}{l}12.8 \\
14.2\end{array}$ \\
\hline \multicolumn{6}{|l|}{ Smokers } \\
\hline $\begin{array}{l}\text { Mechanics } \\
\text { Office workers }\end{array}$ & $\begin{array}{r}419 \\
55\end{array}$ & $\begin{array}{l}103 \\
100\end{array}$ & $\begin{array}{l}12.3 \\
10.2\end{array}$ & $\begin{array}{l}98.7^{\star} \\
94.5\end{array}$ & $\begin{array}{r}11.2 \\
7.2\end{array}$ \\
\hline
\end{tabular}

Table 4. Radiographic findings in 24 mechanics referred for further examination. The profusions are classified according to the ILO-U/C system.

\begin{tabular}{lcccccc}
\hline \multirow{2}{*}{ Year of birth } & \multirow{2}{*}{$\begin{array}{c}\text { Number } \\
\text { of } \\
\text { workers }\end{array}$} & & \multicolumn{5}{c}{ Profusion } \\
\cline { 5 - 7 } \cline { 5 - 6 } & & $0 / 0$ & $0 / 1$ & $1 / 0$ & $1 / 1$ \\
\hline $1911-1919$ & 3 & & - & 1 & - & 2 \\
$1920-1929$ & 12 & $6^{\mathrm{a}}$ & 3 & 3 & $\frac{1}{1}$ \\
$1930-1939$ & 4 & 2 & 1 & $\frac{1}{1}$ & - \\
$1940-1949$ & 2 & $1^{\mathrm{b}}$ & - & - & - \\
$1950-1956$ & 3 & 3 & - & - & 3 \\
\hline Total & 24 & 12 & 5 & 4 & 3 \\
\hline
\end{tabular}

a One man had paresis of the right diaphragm.

b This man had bronchiectasis.

$(\mathrm{N}=99)$ and $3 \%$ for mechanics with $20-29$ years $(\mathrm{N}=184)$ of exposure.

Twenty-four mechanics were referred for further examination: seven because of abnormal spirometries, nine because of abnormal chest radiographs, two because of symptoms, and six because of two or more of the aforementioned reasons. Six were nonsmokers, six ex-smokers, and 12 current smokers. The radiographs of these 24 men were reviewed blindly in 1986 by a chest physician (SL) and classified according to the ILO-U/C system (4). None of these radiographs indicated profusions of more than 1/1 (table 4). No diagnosis of asbestosis was made after these thorough clinical examinations. In two cases transbronchial lung biopsies were taken, but both were found to be normal.

\section{Discussion}

\section{Respiratory function}

Concentrations of asbestos of up to 72 fibers $/ \mathrm{ml}$ have been reported for the repair of brakes with asbestos linings (6). However, the periods of dust exposure are short, mostly about $1 \mathrm{~min}$ or less, and therefore the cumulative dose is low. The risk of contracting asbestosis is highly dependent on the cumulative dose (3). As mechanics are exposed to low doses, any possible 
impairment of the respiratory function should be very low, and such was the case in our investigation (table 2). It may be argued that more sophisticated tests might have revealed impairment of the respiratory function. However, deteriorations of clinical importance are usually detected by simple spirometry. Furthermore, a decrease in vital capacity can be detected in persons exposed to asbestos without changes on chest radiographs (9). Because the results of spirometry were nearly normal, we have concluded that the asbestos exposure of mechanics generally does not impair respiratory function substantially.

\section{Pleural plaques}

Even low exposure to asbestos may cause pleural plaques if the latency time is long enough $(1,7)$. The dose required can be rather low, and environmental exposure to asbestos in the soil seems to be sufficient (5). It is therefore not surprising that the asbestos exposure during brake maintenance seems to be sufficient to cause pleural plaques in mechanics.

\section{Considerations of validity}

The data used in this study were primarily collected by means of a general health survey. However, the examinations were highly standardized and performed by highly qualified physicians and nurses. The referral to further examinations was liberal, and it is improbable that a person with substantial fibrosis remained undiagnosed. The review of 24 radiographs did not indicate any substantial risk of clinically important fibrosis. (See table 4.)

This study was cross-sectional, which may mean underestimated risks. However, a slight impairment of the respiratory function or occurrence of pleural plaques does not normally lead to a change of jobs.

\section{Conclusion}

The asbestos exposure generally experienced by car mechanics may lead to an increased incidence of pleural plaques but does not generally lead to substantial impairment of respiratory function.

\section{References}

1. Becklake MR. Asbestos-related diseases of the lung and other organs: Their epidemiology and implications for clinical practice. Am Rev Respir Dis 114 (1976) 187-227.

2. Berglund E, Birath G, Bjure J, Grimby G, Kjellmer I, Sandqvist L, Söderholm B. Spirometric studies in normal subjects: I Forced expirograms in subjects between 7 and 70 years of age. Acta Med Scand 173 (1963) 185192.

3. Doll R, Peto J. Asbestos: Effects on health of exposure to asbestos. Health \& Safety Commission, Her Majesty's Stationery Office, London 1985.

4. International Labour Office. ILO-U/C 1981: International classification of radiographs of the pneumoconioses. Med Radiogr Photogr 57 (1981) 1-17.

5. Järvholm B, Arvidsson $\mathrm{H}$, Bake B, Hillerdal G, Westrin C-G. Pleural plaques - asbestos - ill-health. Eur J Respir Dis 68 (1986): suppl 145, 1-59.

6. Rohl AN, Langer A, Wolff M, Weisman I. Asbestos exposure during brake lining maintenance and repair. Environ Res 12 (1976) 110-128.

7. Selikoff IJ, Lee DHK. Asbestos and disease. Academic Press, New York, NY 1978.

8. Thiringer G, Blomqvist N, Brolin I, Mattson SB. Pleural plaques in chest $\mathrm{X}$-rays of lung cancer patients and matched controls (preliminary results). Eur J Respir Dis 61 (1980): suppl 107, 119-122.

9. Weill $\mathrm{H}$, Ziskind M, Waggenspack C, Rossiter CE. Lung function consequences of dust exposure in asbestos cement manufacturing plants. Arch Environ Health 30 (1975) 88-97.

Received for publication: 6 May 1987 